\title{
O SIMAVE À LUZ DAS TRÊS GERAÇÕES DE AVALIACCÃO DA EDUCAÇÃO BÁSICA
}

KARLA OLIVEIRA FRANCO ADOLFO IGNACIO CALDERÓN

* As ideias aqui expostas foram discutidas durante o Colóquio Internacional América Latina y Estados Unidos: diálogo de saberes, promovido pelo Consejo Latinoamericano de Ciencias Sociales (CLACSO) e pelo Observatory on Latin America (OLA), que ocorreu em 25 e 26 de maio de 2016, na sede do The New School University, cidade de Nova lorque. Registra-se o agradecimento a João Luiz Horta Neto, Lina Kátia Mesquita de Oliveira

e Maria Inez Barroso Simões pelas

contribuições realizadas para o aprimoramento do artigo, destacando que a responsabilidade do conteúdo é exclusiva dos autores. Este agradecimento também se estende aos membros do Grupo de Pesquisa

em Gestão e Políticas Públicas em Educação da Pontifícia Universidade Católica de Campinas.

\section{RESUMO}

Este artigo apresenta um panorama do processo de implantação do Sistema Mineiro de Avaliação da Educação Pública (Simave), com objetivo de compreender sua trajetória à luz das três gerações de avaliação da educação básica no Brasil, no período entre 2000 e 2013. Por meio de estudo bibliográfico, constatou-se a existência dessas gerações no processo de implantação do Simave. A primeira foi identificada em experiências anteriores ao Simave e nos primeiros anos do referido sistema (2000-2002), período pautado pelo caráter diagnóstico das avaliações. Entre 2003 e 2007, foi identificada a segunda geração, marcada pelo início do programa Acordo de Resultados do Governo de Minas Gerais, envolvendo metas de desempenho e gestão por resultados. A terceira, iniciada em 2007, foi marcada pela segunda fase do Acordo de Resultados, envolvendo o pagamento do prêmio por produtividade atrelado ao desempenho dos alunos nos testes avaliativos do Simave.

PALAVRAS-chaVe SimAVE - AVALIAÇÃo em LARGA ESCALA • EDUCAÇÃO BÁSICA • AVALIAÇÃO DE SISTEMAS. 


\section{SIMAVE A LA LUZ DE LAS TRES GENERACIONES DE EVALUACIÓN DE LA EDUCACIÓN BÁSICA \\ RESUMEN}

Este artículo presenta un panorama del proceso de implantación del Sistema Mineiro de Avaliação da Educação Pública (Simave), con el objetivo de comprender su trayectoria a la luz de las tres generaciones de evaluación de la educación básica en Brasil en el periodo que abarca del 2000 al 2013. Por medio de estudio bibliográfico, se constató la existencia de dichas generaciones en el proceso de implantación del Simave. La primera fue identificada en experiencias anteriores al Simave y en los primeros años del referido sistema (2000-2002), periodo pautado por el carácter diagnóstico de las evaluaciones. Entre 2003 y 2007 se identificó la segunda generación, marcada por el inicio del programa Acuerdo de Resultados del Gobierno de Minas Gerais, que involucraba metas de desempeño y gestión por resultados. La tercera, iniciada en 2007, fue marcada por la segunda fase del Acuerdo de Resultados e implicaba el pago del premio por productividad vinculado al desempeño de los alumnos en las pruebas evaluativas de Simave.

PALABRAS CLAVE SIMAVE - EVALUACIÓN EN GRAN ESCALA • EDUCACIÓN BÁSICA • EVALUACIÓN DE SISTEMAS.

\section{UNDERSTANDING THE SIMAVE IN THE LIGHT OF THE THREE GENERATIONS OF BASIC EDUCATION EVALUATION \\ ABSTRACT}

This article presents an overview of the deployment process of the Sistema Mineiro de Avaliação da Educação Pública (Simave), in order to understand its development in the light of three generations of evaluation of Basic Education in Brazil. These generations were identified through a bibliographical study of the Simave deployment process. The first generation was identified in experiments undertaken before Simave and in the first years of this system (2000-2002), period guided by the diagnostic nature of the evaluations. The second generation of evaluation was identified between 2003 and 2007 and marked by the beginning of the Results Agreement Program of the Government of Minas Gerais involving performance targets and results management. The third generation, started in 2007, was marked by a second phase of the Results Agreement Program, involving the payment of the productivity bonus linked to the performance of students in the Simave evaluation tests.

KEYWORDS SIMAVE • LARGE-SCALE EVALUATION • BASIC EDUCATION • EVALUATION SYSTEMS. 


\section{INTRODUÇÃO}

A década de 1990 foi, no Brasil, marcada pela consolidação da avaliação como um dos elementos estruturantes na elaboração e implementação de políticas públicas com vistas à melhoria da qualidade educacional (SILVA, 2007). O Sistema de Avaliação da Educação Básica (Saeb), criado em 1990 pelo Ministério da Educação (MEC), tendo inovações metodológicas fundamentais em 1995, representa a primeira iniciativa brasileira de estruturação sistemática da avaliação do ensino fundamental (EF) e do ensino médio (EM), promovida com vistas ao conhecimento dos problemas e deficiências do sistema educacional, com intenção de orientar políticas governamentais voltadas para a melhoria da qualidade do ensino. Trata-se de um sistema que acabou estimulando o estabelecimento de sistemas próprios de avaliação em larga escala por parte de estados e municípios (BONAMINO; SOUSA, 2012; BRASIL, 2014).

No Brasil, os processos de avaliação em larga escala são amplos, envolvem aplicações para os diferentes níveis educacionais e são desenvolvidos na forma de processos 
padronizados, organizados e centralizados, no âmbito federal, pelo Instituto Nacional de Estudos e Pesquisas Educacionais Anísio Teixeira (Inep), órgão ligado ao MEC, e, nos âmbitos estaduais e municipais, pelos respectivos entes da federação (SILVA, 2010).

A partir da regulamentação da Lei de Diretrizes e Bases da Educação n. 9394/96 (BRASIL, 1996), de 20 de dezembro de 1996, o Estado passou a assumir, no campo educacional, papel de regulador mediante o desenvolvimento e institucionalização de políticas públicas de avaliação. As concepções sobre o estado avaliador e controlador evidenciaram-se à medida que as avaliações se tornaram eixo central das políticas educacionais. Por meio da vinculação de financiamentos de programas aos resultados fornecidos pelas avaliações externas (GATTI, 2014), observam-se tendências nacionais de caracterizar as avaliações em larga escala como medidas de accountability $^{1}$ (BONAMINO; SOUSA, 2012; BROOKE, 2006; BROOKE; CUNHA, 2011). Tais medidas "significa uma cobrança por bons resultados e a demanda de que cada um dos atores envolvidos assuma sua responsabilidade na produção desses resultados" (BROOKE; CUNHA, 2011, p. 21).

Essa cobrança ocorre a partir da publicação de informações sobre o resultado escolar, segundo as quais a escola e seus dirigentes são responsabilizados pelo nível de desempenho alcançado pela instituição (BROOKE, 2006).

Bonamino e Sousa (2012), por meio de análise dos objetivos e desenhos de iniciativas de avaliações implementadas no Brasil, identificaram três gerações de avaliações da educação em larga escala, as quais são diferenciadas a partir das consequências atribuídas para a escola e para o currículo escolar. Trata-se de recurso analítico, não podendo ser consideradas como interpretação evolucionista, sequencial, de superação de etapas, uma vez que, à medida que vão se sucedendo, as gerações coexistem nas redes de ensino, revelando diversos "usos dos resultados de experiências de avaliação da educação básica em curso no país” (BONAMINO; SOUSA, 2012, p. 386).

A primeira geração de avaliação retrata avaliações de caráter diagnóstico, com a finalidade de acompanhar a evolução 
educacional, tendo seus resultados disponibilizados para consulta pública, porém sem que haja atribuição de consequências diretas para as escolas e para o currículo escolar. As avaliações de segunda e terceira gerações visam a subsidiar, a partir de seus resultados, políticas de responsabilização, havendo, nesses casos, atribuição de consequências para os agentes escolares, criando-se incentivos para que professores se esforcem em prol do aprendizado dos alunos.

No caso das avaliações de segunda geração, as consequências são simbólicas e decorrem da divulgação e da apropriação das informações sobre os resultados da escola pela sociedade. O pressuposto dessas avaliações é que o conhecimento dos resultados favorece a mobilização da equipe escolar em prol da melhoria educacional, além de induzir a pressão dos pais e da comunidade sobre a escola. Essas políticas de responsabilização são caracterizadas pela publicação e divulgação de indicadores de desempenho, sem que haja estabelecimento de consequências explícitas para os atores escolares.

Avaliações de terceira geração, por sua vez, referenciam políticas de responsabilização com consequências sérias, as quais contemplam recompensas decorrentes dos resultados dos alunos e escolas nas avaliações em larga escala. Essas avaliações incluem experiências de responsabilização explicitadas em normas e que envolvem mecanismos de premiação e remuneração em função de metas estabelecidas, como o caso do Sistema de Avaliação do Estado de São Paulo (Saresp), dos sistemas estaduais do Rio de Janeiro (Nova Escola), Pernambuco (Sistema de Avaliação da Educação Básica de Pernambuco - Saepe) e Ceará (Sistema Permanente de Avaliação da Educação Básica do Ceará - Spaece), bem como do sistema municipal de Sobral, no Ceará, uma vez que preveem incentivos salariais por meio de pagamento de bônus em função do alcance de metas estabelecidas (BONAMINO; SOUSA, 2012; BROOKE, 2006; CALDERÓN; OLIVEIRA JÚNIOR, 2013; CALDERÓN; RAQUEL; CABRAL, 2015).

Diante do exposto, o presente artigo, a partir de minucioso estudo bibliográfico resultante da análise de artigos científicos, dissertações de mestrado e teses de doutorados, focaliza o Sistema Mineiro de Avaliação da Educação Pública 
(Simave) e apresenta um panorama de seu processo de implantação e consolidação, com o objetivo de compreender sua trajetória à luz das três gerações de avaliação da educação básica no Brasil, abrangendo o período de 2000 a $2013 .{ }^{2}$ Trata-se de um esforço teórico dos autores para apresentar uma sistematização da trajetória do Simave, com intenção de contribuir para preencher uma lacuna existente na literatura acadêmica, uma vez que, segundo levantamento realizado nos principais bancos de dados que reúnem artigos científicos sobre avaliação educacional, constatou-se a inexistência de artigos que sistematizem o processo de construção e consolidação do referido sistema de avaliação.

\section{PRIMÓRDIOS DA AVALIAÇÃO DA EDUCAÇÃO BÁSICA EM MINAS GERAIS (MG)}

A primeira avaliação educacional em MG foi realizada em 1988, envolvendo apenas o Ciclo Básico de Alfabetização (CBA). Mais tarde, foi empreendido um trabalho mais abrangente, a partir da pesquisa intitulada Avaliação do Ciclo Básico de Alfabetização, coordenada pelo consultor Heraldo Vianna. O planejamento para a aplicação dos testes ocorreu em 1990, último ano de Newton Cardoso (19871990) enquanto governador de MG. Porém os testes foram aplicados apenas em março de 1991, já na gestão de Hélio Garcia (1991-1994) como governador estadual, o qual tinha Walfrido dos Mares Guia Neto como Secretário de Educação (HORTA NETO, 2013; SILVA, 2011).

Durante o governo de Hélio Garcia (1991-1994), foi implantado um programa de reformas no Estado e, em 1991, foram realizados os primeiros estudos, coordenados por Heraldo Vianna, visando a ampliar as pesquisas e implantar um programa de avaliação educacional. O esforço deu origem, em janeiro de 1992, ao Programa de Avaliação do Sistema Estadual de Ensino de Minas Gerais, instituído pela Secretaria de Educação em conformidade com a Constituição Estadual (1989) ${ }^{3}$ (MINAS GERAIS, 1989), diante da necessidade de cooperação entre os agentes da educação no processo de avaliação (HORTA NETO, 2013; SOUZA, 1995, 1999, 2007).

\footnotetext{
3 A Constituição do Estado de Minas Gerais (MINAS GERAIS, 1989, p. 100) regulamenta, dentre outros aspectos, questões acerca da qualidade educacional e sua avaliação. Especificamente no art. n. 195 é determinado que "A educação, direito de todos, dever do Estado e da família, será promovida e incentivada com a colaboração da sociedade, com vistas ao pleno desenvolvimento da pessoa, seu preparo para o exercício da cidadania e sua qualificação para o trabalho". Na sequência, o art.

n. 196 trata da qualidade do ensino, reafirmando a busca pela garantia de um padrão de qualidade mediante "Avaliação cooperativa periódica por órgão próprio do sistema educacional, pelo corpo docente e pelos responsáveis pelos alunos" (MINAS GERAIS, 1989, p. 101).
} 
5 Dados familiares, recursos educacionais, características do corpo docente, programas escolares, propostas curriculares e práticas instrucionais, aluno, formação de atitudes e desempenho escolar.

6 As provas, de caráter objetivo, eram elaboradas visando a identificar fragilidades e necessidades de reforço para a aprendizagem, mensurar o desempenho e avaliar comportamentos

quanto a conhecimentos, sua compreensão e utilização. Havia também aplicação de uma prova de redação visando a verificar em que medida os alunos possuíam capacidade

de expressão escrita (SOUZA, 1995,

1999). Dos questionários dos alunos constavam itens com intuito de obter informações consideradas relevantes para o conhecimento da realidade do estudante: dados pessoais, hábitos escolares, pretensões educacionais, variáveis socioeconômicas e educacionais da família. Nos questionários das escolas,

havia questões para informar quanto ao funcionamento escolar, corpo docente, procedimentos em relação à organização administrativa e à condução pedagógica, conhecimento da maneira como eram ministrados os conteúdos de cada disciplina avaliada

sob o ponto de vista do professor; tais informações eram fornecidas pela direção, representantes do colegiado, especialistas e professores, mediante consenso. Todas as escolas respondiam a um questionário de informações com 50 questões (HORTA NETO, 2013; SOUZA, 1995, 1999; VIANNA; ANTUNES; SOUZA, 1993)

7 De acordo com Souza (2007), no período de 1992 a 1996, as avaliações do programa eram de natureza censitária parcial, uma vez que, embora houvesse participação de todo o quadro discente no processo,

cada aluno era submetido a apenas um dos testes referente a uma das disciplinas avaliadas, havendo, portanto, formação específica para turmas avaliadas. No período de 1997 a 1998, adotou-se a modalidade censitária total, uma vez que todos os alunos das séries participantes eram submetidos aos testes de todas as disciplinas avaliadas.

8 Os alunos da terceira série do EF eram avaliados com intenção de se obterem informações sobre o CBA e verificar em que medida

O mencionado programa visava a criar uma cultura avaliativa ${ }^{4}$ de desempenho escolar com intuito de identificar possíveis falhas de aprendizagem nos anos iniciais do EF e avaliar o desempenho dos professores (SILVA, 2011). Considerava-se que a avaliação deveria ser instrumento relevante de contribuição para a garantia de maior eficiência de todo o sistema e que a atividade avaliativa deveria ir além da mera verificação do rendimento do aluno, servindo, assim, de auxílio para a prática educacional (SOUZA, 1995).

O programa de avaliação tinha objetivo de diagnosticar e compor acervo de dados e informações, fornecendo base para implementação de um plano de melhoria do ensino destinado a intervir na baixa produtividade do sistema educacional e nos índices de retenção dos alunos (SOUZA, 1995, 1999; VIANNA; ANTUNES; SOUZA, 1993). Para tanto, eram avaliadas variáveis relacionadas ao contexto escolar e a fatores não ligados diretamente à escola, ${ }^{5}$ mas que interferiam no processo de ensino e aprendizagem (SOUZA, 1995), a partir de um modelo de avaliação baseado na realidade socioeducativa da cada região e ajustado à realidade de um contexto cultural (VIANNA; ANTUNES; SOUZA, 1993).

Para viabilização do programa, eram utilizados três instrumentos básicos: provas, questionário do aluno e questionário da escola. ${ }^{6}$ De modalidade censitária, ${ }^{7}$ a avaliação incluía exames sistemáticos de cinco séries escolares que representavam o término de ciclo ou de grau de ensino. Eram avaliadas as terceira, quinta e oitava séries do EF, a segunda série do $E M$, além das turmas de terceira e quarta séries do curso de habilitação para o magistério. A escolha das séries estava ligada aos períodos escolares considerados mais críticos para os alunos. ${ }^{8}$

O rendimento das séries selecionadas era avaliado a cada dois anos, períodos denominados ciclos, possibilitando haver um intervalo para executar medidas de intervenção e correção de possíveis fragilidades identificadas antes da próxima avaliação (HORTA NETO, 2013; SILVA, 2011; SOUZA, 1995, 2007). Nos anos pares, era efetuada a avaliação do CBA e das quintas séries do EF, assim como feitos pré-testes das avaliações que seriam aplicadas nos anos ímpares e vice-versa. 
Nos anos ímpares, eram avaliadas as oitavas séries do EF, as segundas séries do EM e as terceiras e quartas séries do curso de habilitação do magistério (HORTA NETO, 2013; VIANNA; ANTUNES; SOUZA, 1993).

Os testes avaliativos do programa envolviam as seguintes áreas do conhecimento: língua portuguesa, matemática, ciências, história, geografia, física, química, biologia e redação, abordadas em questões de múltipla escolha, com exceção para os testes aplicados à terceira série do EF, em razão das características dos alunos. Itens de português e matemática constavam de todas as avaliações; a prova de português visava a avaliar o entendimento e o uso da língua nacional e a prova de redação era aplicada para verificar a capacidade de expressão clara do pensamento por meio de escrita e correção gramatical (HORTA NETO, 2013; SOUZA, 2007; VIANNA; ANTUNES; SOUZA, 1993).

Em 1992, iniciou-se, portanto, a aplicação do primeiro ciclo do programa, que se concretizou de março de 1992 a dezembro de 1993. O segundo ciclo deu-se de março de 1994 a novembro de 1995 (SOUZA, 1995). No total, foram três ciclos de aplicação: 1992-1993, 1994-1995 e 1996-1997. Os dois primeiros ocorreram em governos diferentes: no mandato de Hélio Garcia (1991-1994) e no primeiro ano de Eduardo Azeredo (1995-1998). No terceiro, foram testadas apenas as terceiras e quintas séries do EF (HORTA NETO, 2013; SILVA, 2011). Entre 1992 e 1996, foram realizadas 12 avaliações, sendo cinco no primeiro ciclo, cinco no segundo e duas no terceiro. ${ }^{9}$

Em 1998, o programa de avaliação foi modificado a partir da implantação do Regime de Progressão Continuada no Ensino Fundamental nas escolas da rede estadual e as séries testadas passaram a ser as últimas de cada etapa do EF, quartas e oitavas séries, que eram examinadas a partir das seguintes áreas do conhecimento: língua portuguesa, matemática e redação. Essas avaliações, em vez de serem realizadas a cada dois anos, passaram a ser anuais, com objetivo de verificar se o aluno havia atingido um determinado padrão de desempenho (HORTA NETO, 2013; SOUZA, 1999, 2007). Nesse mesmo ano, foi incluído um questionário do professor com a de essa serie escolar representar mudança na vida do estudante. que, por sua vez, deixa a primeira fase do EF e ingressa na segunda fase com ensino diversificado em conteúdo, metodologias adotadas e pluralidade de professores: os da oitava série do EF eram avaliados por constituir o término do EF; os da segunda série do EM eram avaliados para obter informações sobre o EM e evitar contaminação dos dados com possível preparação para o vestibular; por fim, alunos dos cursos de habilitação para o magistério eram testados para obter informações sobre a formação de professores (HORTA NETO, 2013; SILVA, 2011; SOUZA, 1995, 2007; VIANNA: ANTUNES; SOUZA, 1993).
9 Horta Neto (2013, p. 220)

registrou que, embora a Secretaria de Educação tenha se esforçado para concretizar o programa de avaliação, durante os dois primeiros ciclos, foram desenvolvidos poucos estudos acerca do respectivo programa, nos quais "figuravam técnicos da Secretaria de Educação entre seus autores, reforçando o caráter de pesquisa do programa de avaliação e sua importância para a Secretaria como elemento de estudo da realidade educacional mineira". Considerando que o

respectivo programa de avaliação teve sua origem por meio de pesquisa coordenada por Heraldo Viana, pesquisador da Fundação Carlos Chagas (FCC), para Horta Neto (2013, p. 220), "a FCC não estava envolvida apenas com a concepção do programa de avaliação, mas também realizava esforços para disseminar os resultados obtidos, reforçando o papel de vanguarda da FCC na pesquisa educacional brasileira". 
10 A inspiração para denominação de "Escola Sagarana" encontra-se nas obras de Guimarães Rosa sobretudo por ela expressar a riqueza da cultura regional mineira (AUGUSTO, 2004; FURTADO, 200-; SILVA, 2002)

11 Em 1993, Murílio de Avella Hingel, ministro da Educação e do Desporto do Brasil, visitou a França e conheceu o sistema educacional de avaliação daquele país. Do relatório da visita consta que os resultados das avaliações do sistema educativo francês são publicados mesmo que não reflitam situações favoráveis; os responsáveis pelo setor educacion consideram importante para o governo e para a própria sociedade a mensuração da qualidade do níve de ensino nacional. Nesse contexto. considera-se que a referida visita França contribuiu para a construção do Simave (BARBOSA, 2013).

12 O referido projeto era do Inep, viabilizado para fomentar a avaliação educacional no país, o qual fo aproveitado pela equipe da UFJF para fazer os primeiros ensaios do Simave.

Ao assumir o respectivo projeto, a equipe da UFJF tinha intenção de alargar a experiência e produção de conhecimento na área de avaliação, o que culminou na criação do Centro de Políticas Públicas Avaliação da Educação (Caed), a partir da expansão das atividades do Laboratório de Avaliações e Medidas

Educacionais e com a participação da Faculdade de Educação da UFJF e de professores e especialistas em avaliação educacional do Ministério da Educação da França haja vista

que esse órgão possuía qualificação superior em termos de aprendizagem e de educar para o desenvolvimento cognitivo dos alunos (BARBOSA,

2013). No documento sobre a Escola Sagarana, é destacado que "na formulação do Simave foi feito um acordo com o governo da França para aproveitar a experiência daquele país na área de avaliação educacional" (HORTA NETO, 2013, p. 222). De acordo com a diretora da Superintendência de Avaliação

Educacional da Secretaria de Estado da Educação, Maria Inês Barroso Simões, em entrevista concedida em 2012, os princípios do Simave eram os seguintes: que fosse um sistema de avaliação que tivesse participação da comunidade escolar que começasse, por exemplo, na Secretaria, com a participação dos professores, diretores, sindicato: que fosse, então, participativo; que o foco da avaliação não fosse o aluno, mas sim a escola (BARBOSA, 2013). finalidade de conhecer sua opinião acerca do contexto escolar e obter informações sobre sua vida profissional e prática pedagógica, além de um segundo questionário dirigido ao responsável pelos alunos, visando a obter informações sobre aspectos gerais da escola e avaliar sua participação nas atividades escolares (SOUZA, 1999).

Em 1999, deu-se a mudança de governo em MG, que passou a ser governado por Itamar Franco (1999-2002). Já no início desse ano, o processo de avaliação em curso foi interrompido.

No governo de Itamar Franco, o representante da Secretaria de Estado da Educação foi Murílio Hingel. Nesse período, a alteração na avaliação educacional mineira ficou por conta da implantação do projeto Escola Sagarana. ${ }^{10}$ Dentre os objetivos da política educacional contemplados pela proposta, destaca-se o desenvolvimento de ações em prol da garantia de educação de qualidade, contemplando a avaliação da qualidade do ensino em todos os níveis e modalidades, mediante exames do rendimento dos alunos, metodologias de controle e acompanhamento, estudos e pesquisas. Nesse contexto, a avaliação educacional mineira recebeu nova denominação: Simave (HORTA NETO, 2013; SILVA, 2011).

\section{SIMAVE}

Por meio de parcerias entre representantes de instituições governamentais (Secretaria de Estado da Educação de Minas Gerais - SEE/MG -, Superintendências Regionais de Ensino, Superintendências de Avaliação, MEC, Ministério da Ciência e Tecnologia da França ${ }^{11}$ ), atores políticos (governador e secretário adjunto) e professores da Universidade Federal de Juiz de Fora (UFJF), foi criado o Simave, sendo essa uma iniciativa que deveria permitir incorporar outros tipos de avaliação, em razão da diversidade e peculiaridade de cada região de MG. A princípio, o processo de implantação do Simave ocorreu por meio de um projeto piloto na região de Juiz de Fora, o qual ficou conhecido como Programa Piloto de Avaliação da Rede Pública de Ensino Fundamental. ${ }^{12}$

As avaliações do Simave começaram de forma censitária na gestão de Itamar Franco (1999-2002), sendo incorporadas 
à agenda do primeiro mandato do governo Aécio Neves (2003-2006) como parte do programa de reforma denominado "Choque de Gestão: pessoas, qualidade e inovação na administração pública". ${ }^{13}$ Em 2000, o Simave foi regulamentado pela SEE/MG, a qual se mantém à frente de sua coordenação, que avalia o desempenho dos alunos atendidos pela rede pública de ensino, visando a fomentar mudanças em prol de uma educação de qualidade no estado (MINAS GERAIS, 2013).

Como instrumento de avaliação do Simave, instituiu-se, a princípio, o Programa de Avaliação da Rede Pública de Educação Básica (Proeb). O Simave/Proeb foi, assim, regulamentado em 2000, no governo de Itamar Franco (1999-2002), com objetivo de medir o desempenho dos alunos em língua portuguesa e matemática. Trata-se de um programa de avaliação que visa a avaliar as escolas da rede estadual de ensino por meio da aplicação de testes no final do mês de novembro, com ciclos de verificação completos a cada dois anos (ARAÚJO; SILVA, 2011; CARVALHO, 2010; CORREA, 2007; HORTA NETO, 2013; SILVA, 2007; SOARES, 2005).

Em 2005, foram instituídos outros dois instrumentos de avaliação do Simave: Programa de Avaliação da Alfabetização (Proalfa) e Programa de Avaliação da Aprendizagem Escolar (Paae).

O Proeb e o Proalfa atuam na avaliação externa do sistema de ensino, enquanto o Paae incide na avaliação interna da escola. Para desenvolvimento do Paae, há parceria com o Instituto Avaliar, ${ }^{14}$ enquanto que a coordenação das avaliações do Proeb e Proalfa é responsabilidade da UFJF, por meio do Caed, vinculado à Faculdade de Educação (ARAÚJO; SILVA, 2011; BURGOS; SANTOS; FERREIRA, 2012; CARVALHO, 2010; HORTA NETO, 2013; MINAS GERAIS, 2013; SOARES, 2005).

\section{PROEB}

13 Com o choque de gestão, foi mplantada na administração pública a metodologia de gestão por resultados, denominada Gestão Estratégica dos Recursos e Ações do Estado (Geraes). O objetivo foi reformar, reorganizar e modernizar - estado a partir de uma lógica de racionalização dos gastos públicos com maior eficiência, com intuito de implantar o modelo gerencial, tendo como princípio fundamental a melhoria dos resultados por meio de gerenciamento diferenciado,

reforçando o ajuste fiscal e mantendo investimentos estratégicos, prevendo o alinhamento entre o desenvolvimento de pessoas, objetivos organizacionais e avaliação dos resultados das políticas públicas (BARBOSA, 2013; SILVA, 2011).
$14 \mathrm{Com}$ especialidade em pesquisa e processos de avaliação, o Instituto Avaliar é uma organização da sociedade civil, sem fins lucrativos, que tem, em seu corpo diretivo, pesquisadores de importante trajetória acadêmica, tais como Lúcia Alves Faria Mattos (presidente), Nigel Brooke (vice-presidente), Maria Alba de Souza, dentre outros. A parceria desse instituto com o Simave ocorreu por meio de processo licitatório público, de caráter técnico, conforme normas estabelecidas por lei.

O Proeb integra o Simave desde a primeira edição, em 2000, e avalia alunos dos quinto e nono anos do EF e do terceiro ano do EM das escolas da rede pública de ensino de MG (MINAS GERAIS, 2013).

Em 2000, o Simave/Proeb testou as áreas de língua portuguesa e matemática; em 2001, as áreas de ciências humanas 
15 Conforme informação apresentada por Silva (2007), não ocorreu o segundo ciclo das avaliações porque a SEE/MG pretendia concentrar a portuguesa e matemática.
16 Esse sistema envolvia uma série de materiais escritos e em vídeo relativos ao Simave e seus resultados para serem discutidos quinzenalmente em reuniões nas escolas. As discussões eram sintetizadas e registradas en documentos e encaminhadas para as Regionais de Ensino que, por sua vez, identificariam as necessidades das escolas, visando a desenvolver ações de apoio (HORTA NETO, 2013).

17 ○ padrão "recomendado" é destinado a alunos capazes de realizar tarefas que exigem habilidades mais sofisticadas e que são esperadas para o período escolar em que se encontram, o "intermediário" para alunos que demonstram ter ampliado suas habilidades e o "baixo" para alunos que desenvolveram competências e habilidades abaixo do esperado para o período de escolarização em que se encontram matriculados (HORTA NETO, 2013). e ciências da natureza. Em 2002, quando deveria repetir o ciclo de 2000, examinou apenas língua portuguesa. Em 2003, primeiro ano do governo de Aécio Neves (2003-2006), quando o ciclo de 2001 deveria se repetir, foi testado apenas o desempenho em matemática. Em 2004 e 2005, não houve aplicação dos testes do Proeb. ${ }^{15}$ Desde 2006, o Proeb vem sendo aplicado regularmente todos os anos, avaliando língua portuguesa e matemática (HORTA NETO, 2013; MINAS GERAIS, 2013; SILVA, 2007, 2011; SOARES, 2005; SOARES; ANDRADE, 2006).

Além dos testes cognitivos, alunos, professores e diretores respondem a questionários contextuais. Os alunos respondem a questionário com perguntas relacionadas ao padrão de vida, características culturais, hábitos de estudos, características familiares, apoio familiar e ao ambiente escolar. No questionário dos professores, são apresentadas questões relativas às características sociodemográficas, formação profissional e prática pedagógica. O questionário do diretor é aplicado para apurar dados relativos às características sociodemográficas, bem como titulação e características do exercício profissional, além de avaliação geral das condições da escola e do trabalho dos professores (FERNANDES et al., 2008; SILVA, 2011).

Os primeiros resultados do Proeb começaram a ser discutidos na rede de ensino a partir da instalação do Sistema de Ação Pedagógica. ${ }^{16}$ A divulgação dos resultados é realizada por meio de quatro instrumentos: Revista do Sistema de Avaliação, Revista do Gestor, Boletim Pedagógico da Escola e Revista Fatores Associados (HORTA NETO, 2013; SILVA, 2005, 2011; SOARES, 2005).

Os resultados do Proeb também são divulgados por meio de alguns padrões de desempenho estudantil que classificam o desempenho das escolas segundo o que os alunos seriam capazes de executar, com base nos testes aplicados: recomendado, intermediário e baixo. ${ }^{17} \mathrm{O}$ Proeb tem seus resultados divulgados, mantendo-os disponíveis às escolas participantes. Cada escola recebe um boletim de avaliação, um boletim pedagógico e a Revista do Professor, além do boletim do qual constam os resultados de sua escola. Para acesso à 
realidade de outras escolas do estado, são disponibilizados os resultados de todas as unidades de MG no site da Secretaria Estadual (SILVA, 2011).

\section{PROALFA}

O Proalfa passou a compor as avaliações do Simave em 2005, com objetivo de medir os níveis de alfabetização dos alunos da rede pública de ensino, e, de acordo com Horta Neto (2013), representa um programa que retoma uma das ideias do programa de avaliação coordenado por Heraldo Vianna, em 1992, no que tange ao acompanhamento do processo de alfabetização nos anos iniciais do EF, por meio da aplicação de testes de língua portuguesa e matemática para alunos do quarto ano do EF, com intenção de avaliar a alfabetização do ano anterior.

Os testes que compõem a avaliação do Proalfa são elaborados pelo Centro de Alfabetização, Leitura e Escrita e são aplicados pelo Caed (RIANI; SILVA; SOARES, 2012). O referido programa realiza uma avaliação anual aplicada de duas maneiras: amostral e censitária. ${ }^{18}$

Desde o início da aplicação das avaliações, em 2005, o Proalfa passou por sucessivas ampliações. Em 2005, a avaliação foi aplicada, de maneira amostral, para alunos da rede pública estadual que estavam cursando o segundo ano do EF. Em 2006, a avaliação foi amostral para alunos do segundo ano do EF e censitária para alunos do terceiro ano do EF. No período de 2007 a 2013, a avaliação foi amostral para alunos dos segundo e quarto anos do EF e censitária tanto para alunos do terceiro ano do EF quanto para alunos com baixo desempenho (MINAS GERAIS, 2013).

Burgos, Santos e Ferreira (2012), ao escreverem sobre aspectos específicos do Proalfa, registraram que os resultados da primeira avaliação do programa, realizada em 2005, revelaram que quase metade dos alunos da etapa avaliada não estava alfabetizada após os três primeiros anos do EF. Em 2007, primeiro ano do segundo mandato do governador Aécio Neves (2007-2010), no qual a representante da Secretaria de Educação era Vanessa Guimarães, foi apresentado, como estratégia para reverter
18 A avaliação amostral é realizada por meio do teste de língua portuguesa aplicado para amostras de alunos dos segundo e quarto anos do EF, com intuito de subsidiar o processo de intervenção pedagógica na escola. A avaliação censitária é realizada por meio de testes aplicados para alunos do terceiro ano do EF e para os alunos do quarto ano do EF que, na avaliação do ano anterior. apresentaram baixo desempenho (BURGOS; SANTOS; FERREIRA, 2012 CARVALHO; MACEDO, 2010; HORTA NETO, 2013; RIANI; SILVA; SOARES,

2012). Todos os alunos respondem ao mesmo teste e, com base nos resultados, são gerados relatórios de desempenho por escola e por aluno (HORTA NETO, 2013). 
19 Trata-se de uma política do governo de MG, implantada no mandato Aécio Neves (2003-2006), que buscava identificar escolas que estivessem mais próximas do ideal de xcelência e que pudessem influenciar as demais e resgatar a crença nas possibilidades de uma educação

pública de qualidade (MINAS GERAIS, 2004a, 2004b). De acordo com Brooke e Cunha (2011), o Projeto Escolas-Referência, iniciado em 2004, com a seleção de 223 escolas,

visava a transformar as escolas escolhidas em exemplos de educação de qualidade no estado. Apesar de não ter sido criado como política de

incentivo ou premiação, o projeto e situa nessa categoria do sistema classificatório, uma vez que promove investimentos variados nas escolas beneficiadas, porém condicionados a que essas repassem as boas práticas,

acompanhando e apoiando sua

implantação em outras escolas de desempenho mais fraco (BROOKE: CUNHA, 2011) esse quadro, o Programa de Intervenção Pedagógica (PIP), o qual retrata uma política pública em prol da melhoria do nível de desempenho dos alunos, alfabetizando-os no tempo adequado e possibilitando que sigam, com êxito, até as últimas séries do EF.

\section{PAAE}

O Paae foi criado para as escolas da rede estadual de MG e tem concepção pedagógica traduzida para um sistema on-line, visando a identificar necessidades imediatas de intervenção pedagógica. Para tanto, as escolas geram provas a partir da utilização de ferramentas de um Banco de Itens formado por questões objetivas, diferenciadas em três níveis de dificuldade e vinculadas aos tópicos e habilidades a serem ensinados e aprendidos.

No que tange a aspectos do histórico desse programa de avaliação, o Paae foi planejado para a educação básica em 2003, primeiro ano do primeiro mandato de Aécio Neves (2003-2006) como governador do estado. Nos dois anos posteriores, a estrutura do programa e o Banco de Itens composto por 10.000 tópicos foram desenvolvidos para os anos finais do EF e EM. De 2005 a 2009, o Paae foi gradativamente implantado no primeiro ano do EM, começando em 2005, com participação de 72 escolas no projeto piloto do Banco de Itens; em 2006 e 2007, foi aplicado em 226 escolas-referência, ${ }^{19}$ em 2008, foi ampliado para 2.000 escolas de EM e, em 2010, finalmente institucionalizado.

O Paae é composto por três avaliações aplicadas de forma on-line ou impressas: avaliação diagnóstica, denominada também primeira prova, aplicada no início do ano letivo; avaliação da aprendizagem anual, denominada segunda prova, aplicada no final do ano letivo; e avaliação contínua, que ocorre no intervalo entre as outras duas avaliações, visando a acompanhar o desenvolvimento da aprendizagem, verificar fragilidades e orientar o planejamento das atividades didáticas. As avaliações diagnóstica e da aprendizagem anual são obrigatórias, enquanto a avaliação contínua é opcional para as escolas. 
Além de avaliar a aprendizagem, o programa possibilita verificar os conhecimentos dos professores, uma vez que o acesso ao gabarito só é liberado depois que eles respondem às questões aplicadas. Desse modo, ao serem computados os resultados dos testes resolvidos por professores e alunos, a Secretaria tem possibilidade de identificar os erros e acertos não apenas dos alunos, mas também dos professores (SILVA, 2011).

\section{- SIMAVe E AS tRÊS GERAÇÕES de AVALIAÇÃo DA EDUCAÇÃO BÁSICA}

Ao reconstruir os processos da história relativamente recente de MG, constatou-se que a experiência mineira de avaliação da educação básica reflete processos e tendências que vêm se configurando em nível nacional, especificamente no que se refere à caracterização apresentada por Bonamino e Sousa (2012) a respeito das chamadas três gerações de avaliação da educação básica no Brasil, uma vez que, conforme será apresentado, as distinções propostas pelas autoras, ao estabelecer as três gerações, também são constatadas na trajetória das avaliações da educação básica implantadas em MG.

PRIMEIRA GERAÇÃO: DAS PRIMEIRAS INICIATIVAS

AVALIATIVAS AOS PRIMÓRDIOS DO SIMAVE (1992-2002)

A partir da definição apresentada por Bonamino e Sousa (2012) quanto às três gerações da avaliação educacional no Brasil, é possível afirmar que a primeira geração da avaliação da educação básica em MG visualiza-se durante o processo de implantação e aplicação dos testes avaliativos do Programa de Avaliação do Sistema Estadual de Ensino de Minas Gerais, que ocorreu no período de 1992 a 1999, o qual representa a primeira iniciativa de avaliação da educação básica em MG. As avaliações do referido programa tinham caráter diagnóstico e não foram identificados registros quanto à atribuição de consequências para as escolas a partir dos resultados obtidos. A inferência é que esse programa de avaliação foi desenvolvido de modo a garantir a autonomia pedagógica dos envolvidos no processo de ensino e aprendizagem e como 
$20 \bigcirc$ Acordo de Resultados foi introduzido no último ano do governo de Itamar Franco (1999-2002) (SILVA,
2011) e teve continuidade no primeiro mandato do governo de Aécio Neves (2003-2006) meio de gerar informações sobre a educação mineira para subsidiar decisões em prol de sua melhoria.

A designação do programa como avaliação de primeira geração se justifica pelo caráter diagnóstico dos exames realizados, além do objetivo de compor um acervo de dados e informações sobre as escolas, convertendo-se em uma base para implementação de um plano de melhoria do ensino capaz de intervir na baixa produtividade do sistema educacional e nos índices de retenção dos alunos (SOUZA, 1995, 1999; VIANNA; ANTUNES; SOUZA, 1993), sem que os resultados das avaliações fossem utilizados para introdução de políticas de responsabilização de professores, diretores e gestores. Essa característica das primeiras iniciativas de avaliação em MG, enquanto avaliação de primeira geração, também é constatada nos primórdios do Simave, no período entre 2000 e 2003, em razão da consideração de que o respectivo sistema não foi estruturado com a intenção de estabelecer mecanismos de comparações entre escolas, mas sim com finalidade diagnóstica a partir dos seguintes objetivos: levantar dados e informações para subsidiar tomadas de decisões sobre o desenvolvimento do processo de ensino, criar clima de cooperação entre os atores escolares e avaliar o currículo (TRIPODI, 2012).

Em 2003, quando Aécio Neves (2003-2006) assumiu pela primeira vez a gestão do governo estadual, as avaliações do Simave assumiram outras perspectivas. Inseridas na primeira fase do programa "Choque de Gestão: pessoas, qualidade e inovação na administração pública", denominada "Acordo de Resultados", ${ }^{20}$ as avaliações mineiras passaram a ser caracterizadas, no contexto assumido, como avaliações de segunda e terceira gerações, em razão da introdução de mecanismos de responsabilização como "alternativa de transferência da responsabilidade da melhoria da qualidade do ensino a professores e gestores escolares" (ARAÚJO; SILVA, 2011, p. 217), a partir de estratégia de publicação de resultados com vistas a

\footnotetext{
[...] pressionar as escolas e profissionais da educação, subentendendo que as estratégias de competição, exclusivamente mercadológicas, compõem a alternativa para melhorar a educação. (ARAÚJO; SILVA, 2011, p. 218)
} 
Considerando os três instrumentos de avaliação do Simave, ${ }^{21}$ há registros de utilização de seus resultados para subsidiar políticas de responsabilização apenas para os casos dos testes promovidos pelo Proeb e pelo Proalfa, o que permite sua identificação como programas de segunda e terceira gerações, conforme apresentado nas seções seguintes. Entretanto, no que tange à caracterização do Paae no âmbito das três gerações, é possível enquadrar esse instrumento de avaliação no contexto das avaliações de primeira geração, em virtude de seu cunho diagnóstico, com objetivo de acompanhar o desenvolvimento da aprendizagem, verificar as fragilidades e orientar o planejamento docente, sem atribuir consequências vinculadas aos resultados mensurados; trata-se de um programa de apoio ao professor que foi desenvolvido para monitorar se o currículo escolar estava sendo trabalhado.

SEGUNDA GERAÇÃO: DAS METAS DE DESEMPENHO À GESTÃO POR RESULTADOS (2003-2006)

Durante um período de 12 anos (2003-2014), o governo de MG foi gerido por representantes do Partido da Social Democracia Brasileira (PSDB): Aécio Neves (2003-2006; 2007-2010) e Antônio Anastasia (2011-2014). A gestão do partido foi marcada por um programa de reforma administrativa do estado, denominado "Choque de Gestão: pessoas, qualidade e inovação na administração pública”, o qual teve a primeira fase instituída no primeiro mandato de Aécio Neves (2003-2006), com a denominação "Acordo de Resultados". ${ }^{22}$

Essa primeira iniciativa do Choque de Gestão em MG prevê, por meio da Lei n. 14.694 de 30 de julho de 2003 (MINAS GERAIS, 2003), contratualização de resultados com vistas à ampliação de autonomia gerencial, orçamentária e financeira dos órgãos e entidades a partir de acordos entre seus dirigentes e o poder público, por meio da fixação de metas de desempenho (SILVA, 2011; TRIPODI, 2012). O

22 Acordo de Resultados representa um instrumento de pactuação que estabelece, entre órgãos e entidades do Poder Executivo estadual e autoridades que sobre eles tenham poder hierárquico, quais compromissos e metas devem ser atingidos, com base em indicadores preestabelecidos, concedendo, aos acordados autonomia gerencial e, em caso de desempenho satisfatório, pagamento de prêmio por produtividade aos servidores como incentivo. governo de MG foi um dos primeiros a incorporar o modelo de gestão por resultados, iniciado em 2003, com proposta implantada a partir da utilização da metodologia Geraes, tendo como ponto inicial a definição de Projetos 
23 Foram definidos os seguintes Projetos Estruturadores: 1) desempenho e qualificação dos professores; 2) escola de temp integral; 3) novos padrões de gestão

atendimento da educação básica; 4) sistemas de avaliação da qualidade do ensino e das escolas (TRIPODI, 2012)
Estruturadores ${ }^{23}$ para garantir o desenvolvimento do estado (AUGUSTO, 2010; BARBOSA, 2013; BROOKE; CUNHA, 2011; HORTA NETO, 2013; SILVA, 2011).

O Simave é considerado um dos pilares dos referidos Projetos Estruturadores, em razão da importância da dimensão dos indicadores educacionais fornecidos a partir dos resultados de suas avaliações. O Acordo de Resultados é, portanto, na área da educação, concretizado a partir do estabelecimento e cumprimento de metas, as quais são acompanhadas mediante contrato entre o governo estadual e a Secretaria de Educação. O alcance das metas é monitorado por meio de indicadores e os resultados das avaliações pertencentes ao Proeb e Proalfa são utilizados como referência para ordenar ações do governo estadual no campo educacional. As metas do Acordo de Resultados, na área da educação, apontam para a melhoria da qualidade educacional, principalmente no que tange à elevação dos indicadores. Nesse sentido, a prioridade volta-se para o aumento do desempenho dos alunos em língua portuguesa e matemática nos testes do Simave, os quais são tomados como indicadores de qualidade (BARBOSA, 2013; HORTA NETO, 2013).

Nesse contexto, o Acordo de Resultados representou a institucionalização de medidas de responsabilização que passaram a atingir as escolas e as pessoas que nelas trabalham (AUGUSTO, 2010; SILVA, 2011). Portanto, as práticas do governo estadual relativas às avaliações em larga escala para a educação básica deixaram de ser meramente diagnósticas e convergiram para o estabelecimento de metas e divulgação dos resultados dos alunos no Simave, por escola e rede de ensino, sem que houvesse, inicialmente, vinculação de prêmios ou punições a esses números, tal como é característico das avaliações de segunda geração assinaladas por Bonamino e Sousa (2012).

Há também, na SEE/MG, uma política de formação continuada que é formulada a partir dos resultados das avaliações do Simave. Tal política é denominada PIP e visa a fazer com que as escolas com os piores desempenhos recebam visitas de uma equipe pedagógica especializada para discutir e trabalhar lacunas observadas na análise dos resultados aferidos pelos exames (BROOKE; CUNHA, 2011). 
O PIP começou a ser desenvolvido em 2006, com intuito de atingir a meta de todas as crianças serem alfabetizadas até oito anos de idade. Inicialmente, foi elaborado a partir da discussão dos resultados das avaliações do Proalfa e, com o tempo, expandido com objetivo de implantar os Conteúdos Básicos Comuns nos anos finais do EF e EM, a partir das medições do Proeb. Envolve equipes da Secretaria das Superintendências Regionais e das escolas, visando a analisar os índices obtidos no Proeb e no Proalfa e, a partir de então, propor um plano de intervenção pedagógica em prol da melhoria do desempenho aferido. Tal plano de intervenção, bem como seu acompanhamento, é realizado por profissionais designados "Especialistas em Educação Básica", sendo que esses profissionais atuam nas escolas, com trabalho focado nas avaliações educacionais e na melhoria dos indicadores. A atuação a partir do PIP é, portanto, focada nas áreas de conhecimento avaliadas pelo Proalfa e Proeb, visando a cuidar para que as metas estabelecidas pela Secretaria para as escolas sejam cumpridas (HORTA NETO, 2013).

Nesse contexto de reflexão acerca dos resultados das avaliações, houve a iniciativa de envolver profissionais especialistas para auxiliar os professores em suas ações em sala de aula e, assim, reorganizar o sistema de avaliação. Portanto, tem-se que o ponto forte foi o trabalho com os resultados dos exames em larga escala, o qual foi desenvolvido a partir da instituição do Dia da Avaliação, denominado "Dia D”, com a finalidade de induzir os atores escolares a ler, analisar e discutir sobre os resultados da sua escola no Simave, objetivando refletir para a melhoria da aprendizagem dos alunos (BURGOS; SANTOS; FERREIRA, 2012; MINAS GERAIS, 2013), tal como ocorre, por exemplo, no estado de São Paulo, no qual também é instituído um dia destinado especificamente para discutir os resultados das avaliações, nomeado como "Dia do Saresp na escola” (CALDERÓN; OLIVEIRA JÚNIOR, 2013).

Diante do contexto apresentado acerca da iniciativa de refletir sobre os resultados do Simave, tem-se que esse momento de reflexão é marcado por uma responsabilização simbólica, uma vez que há a concepção de que analisar os índices das avaliações externas, estudar a concepção dessas avaliações, 
conhecer as metas propostas e planejar as intervenções adequadas é responsabilidade de toda a comunidade escolar (BURGOS; SANTOS; FERREIRA, 2012; MINAS GERAIS, 2008b).

Assim, a referida responsabilização simbólica também se enquadra na perspectiva apresentada por Bonamino e Souza (2012) acerca das avaliações de segunda geração, as quais se definem, conforme já apresentado anteriormente, por atribuir responsabilização simbólica decorrente da divulgação e apropriação das informações sobre o desempenho da escola, pelos pais e pela sociedade. O pressuposto dessa geração da avaliação é que o conhecimento dos resultados favorece a mobilização das equipes escolares para melhoria da educação, induzido, também, pela pressão dos pais e da comunidade sobre a escola. Nessa geração da avaliação, entretanto, não são atribuídas recompensas em função do desempenho dos alunos e das escolas nas provas do Simave.

Em 2012, quando o representante do governo do estado de MG era Antônio Anastasia (2011-2014), também do PSDB, algumas escolas da rede receberam placas informativas contendo os resultados do último Índice de Desenvolvimento da Educação Básica (Ideb). No final desse mesmo ano, foi anunciado que, no início de 2013, seriam distribuídas a todas as escolas da rede estadual as referidas placas contendo os resultados do Ideb de 2011, para turmas de quinto e nono anos do EF, e do Proeb, para o caso das escolas que atendiam ao EM. Além disso, foram divulgadas as médias da rede pública do município e a da rede estadual de MG, com intenção de responsabilizar a escola e sua equipe quanto à melhoria do desempenho dos estudantes nas avaliações externas.

Nas placas há uma gradação de cores para a apresentação das notas, iniciando com vermelho e caminhando para o verde, o que, conforme interpretação apresentada por Horta Neto (2013), possibilita a identificação de aspectos negativos relacionados à cor vermelha, de alerta relacionados à cor amarela e positivos relacionados ao verde. O destaque para a expressão "nota da escola" abre possibilidade para interpretação relacionada à mensagem de classificação das escolas no contexto da rede estadual de ensino (HORTA NETO, 2013), tal como foi realizado no estado de São Paulo, onde institui- 
ções de ensino foram classificadas a partir dos resultados nas avaliações do Saresp por cores diferenciadas, servindo de parâmetro para definição de bônus para professores e gestores (CALDERÓN; OLIVEIRA JÚNIOR, 2013).

A medida de fixação de placas repercutiu no âmbito acadêmico por meio de discussões acerca do impacto na área pedagógica e na gestão escolar. Os debates são marcados por opiniões que divergem conforme a concepção teórica dos especialistas educacionais. Alguns defendem que publicar os resultados em placas fixadas nas escolas é uma possibilidade de envolver e mobilizar a comunidade em prol de medidas direcionadas para a melhoria da aprendizagem e, consequentemente, dos resultados. Outros negam a eficácia dessa medida, sob a consideração de que não é positivo para a evolução dos processos de ensino e aprendizagem, na medida em que rotula as unidades escolares e tende a proporcionar classificação e competição entre as instituições de ensino.

A fixação de placas com informativo sobre as notas do Ideb e Proeb é, no entanto, uma medida do Estado limitada à divulgação de desempenho dos estudantes de modo a permitir comparações, entre redes e escolas, configurando, assim, uma política de responsabilização branda, tal como é característico das experiências de segunda geração apresentadas por Bonamino e Sousa (2012).

TERCEIRA GERAÇÃO: IMPLANTAÇÃO DO PRÊMIO POR PRODUTIVIDADE (2007-2013)

No segundo mandato de Aécio Neves (2007-2010), foi implantada a segunda fase do programa "Choque de Gestão", denominada "Estado para Resultados", por meio da qual houve incorporação de práticas de monitoramento e avaliação (TRIPODI, 2012), e a qualidade educacional passou a ser relacionada ao desempenho dos alunos nas avaliações do Simave, implementando-se mecanismos de incentivo à concessão de prêmio por produtividade aos servidores.

Dentre as ações executadas para garantir a qualidade da educação, Tripodi (2012) destacou a elaboração de um novo plano de carreira, o qual passou a prever a promoção e progressão dos servidores baseadas no mérito aferido por meio 
de avaliação anual de desempenho individual. Outra medida instaurada foi a instituição do Acordo de Resultados e remuneração variável, traduzida no prêmio por produtividade, esse, por sua vez, determinado pela execução de metas estabelecidas, pactuadas e sujeitas a acompanhamento mediante contrato de gestão com órgãos da administração pública.

Apesar de a concepção do prêmio por produtividade ter sido implantada em 2004, no âmbito da primeira fase do programa Choque de Gestão, denominada Acordo de Resultados, o pagamento do respectivo prêmio é realizado em MG desde 2007. Nesse ano, conforme informação apresentada por Tripodi (2012), foi firmado o primeiro Acordo de Resultados da SEE, na perspectiva do Estado para Resultados, sendo a concessão de pagamento de prêmio por produtividade aos servidores o principal mecanismo de incentivo para o alcance de metas estabelecidas.

A partir de 2008, o modelo de avaliação de desempenho foi reformulado pela Lei n. 17.600, de 1 de julho de 2008 (MINAS GERAIS, 2008a), a qual trata da avaliação de Desempenho Institucional, destacando vinculação do prêmio por produtividade ao balanço final no Simave/Proeb.

A partir do desempenho da Secretaria e das escolas frente às metas estabelecidas pelo já mencionado Acordo de Resultados, os servidores passaram a receber bonificação em dinheiro, paga no semestre seguinte ao da apuração dos testes. O monitoramento dessas metas ocorre por meio de indicadores, entre os quais estão o percentual de alunos classificados no nível recomendado pelo Proeb e pelo Proalfa e a proficiência média em suas provas. Além desses indicadores, são também consideradas as taxas de distorção idade-série e de fluxo escolar, calculadas pelo Inep (HORTA NETO, 2013).

O pagamento do prêmio por produtividade é realizado de acordo com o alcance das metas determinadas, efetivando-se somente se o Estado registrar resultado satisfatório. Além disso, embora calculado individualmente, o valor dessa bonificação é proporcional ao cumprimento das metas por equipes de trabalho, considerando o valor da última remuneração do período de referência, os dias efetivamente trabalhados e a avaliação institucional. 
Uma das consequências do fato de os indicadores estarem vinculados aos componentes curriculares avaliados pelo Simave e gerar pagamento de bônus para todos os professores, registrada por Brooke e Cunha (2011), está relacionada à maneira de pensar dos professores de outras disciplinas e anos escolares que não são contemplados pelas avaliações do Simave. Há dificuldade de compreensão desses profissionais quanto ao Acordo de Resultados, no sentido de acharem que não podem contribuir para o alcance das metas, uma vez que não consideram a possibilidade de colaborarem com o ensino de língua portuguesa e matemática por meio do desenvolvimento de um trabalho conjunto ou paralelo que envolva, além dos conteúdos das disciplinas que lecionam, aspectos dos conteúdos que são avaliados nos testes do Simave. Registrando que, caso as metas sejam atingidas, eles também recebem o prêmio sem perceber que o mesmo retrata o trabalho realizado por toda a equipe escolar. Os autores afirmam, ainda, que apesar

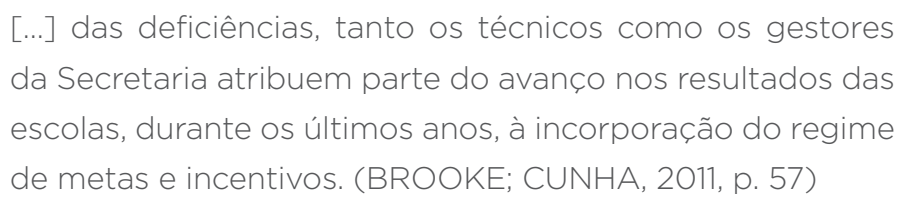

[...] das deficiências, tanto os técnicos como os gestores da Secretaria atribuem parte do avanço nos resultados das escolas, durante os últimos anos, à incorporação do regime de metas e incentivos. (BROOKE; CUNHA, 2011, p. 57)

Ao comparar os sistemas de avaliação dos estados de São Paulo, Pernambuco, Ceará e Rio de Janeiro (BONAMINO; SOUSA, 2012; BROOKE, 2008; CALDERÓN; OLIVEIRA JÚNIOR, 2013), os quais possuem suas avaliações caracterizadas como sendo de terceira geração, é possível classificar a iniciativa mineira de pagamento de prêmio por produtividade igualmente como política de responsabilização com consequências fortes, a qual contempla recompensas em decorrência dos resultados dos alunos e escolas nas avaliações de larga escala, a partir da implementação de política de incentivos salariais, na forma de pagamento de prêmio por produtividade para os servidores que atingirem as metas estabelecidas, tal como é próprio das políticas de terceira geração, descritas por Bonamino e Sousa (2012). 


\section{CONSIDERAÇÕES FINAIS}

Com intuito de contextualizar o processo de institucionalização do Simave, retratamos o panorama de seu processo de implantação e consolidação, verificando que, de 1992 até 2013, as avaliações externas do sistema educacional de MG se articulam com as três gerações de avaliações em larga escala da educação básica no Brasil, propostas por Bonamino e Sousa (2012), não na perspectiva sequencial e etapista, mas na perspectiva de um processo no qual se evidencia a coexistência das diferentes gerações nas redes de ensino, revelando diversos usos e consequências em função dos resultados obtidos nas avaliações.

O sistema de avaliação educacional mineiro passou, inicialmente, por uma proposta de avaliação formativa até se transformar num modelo cujas diretrizes passaram a ser voltadas para a medição de resultados, a partir do desenvolvimento de ações em prol do fortalecimento da capacidade gerencial do governo, visando à sua funcionalidade quanto às políticas de regulação do sistema.

Foram identificados três grandes momentos no processo de consolidação do Simave. O primeiro compreendeu o período de 1992 a 2002 e foi caracterizado pela aplicação dos testes avaliativos que compunham o Programa de Avaliação do Sistema Estadual de Ensino de Minas Gerais e, ainda, pela aplicação das avaliações do Simave no período de 2000 a 2002, as mesmas que possuíam caráter diagnóstico, sem haver atribuição de consequências para as escolas a partir dos resultados aferidos por meio de testes cognitivos.

O segundo momento compreendeu o período de aplicação do Simave entre 2003 e 2006 e foi marcado pela primeira fase do programa Acordo de Resultados, o qual representou a institucionalização de medidas de responsabilização dirigidas às escolas e às pessoas que nelas trabalham, sem haver vinculação de consequências, por meio de prêmios ou punições, a partir dos resultados das avaliações do Simave. Esse momento foi caracterizado pela divulgação dos resultados, deixando o caráter meramente diagnóstico e passando para o estabelecimento de metas e divulgação dos resultados, sem estabelecimento de consequências. 
Compreendendo o período a partir de 2007, o terceiro momento foi marcado pela segunda fase do Acordo de Resultados e foi caracterizado por haver recompensas em decorrência dos resultados dos alunos e escolas nas avaliações do Simave, por meio de ações envolvendo incentivos salariais a partir do efetivo pagamento de prêmio por produtividade para os servidores que atingissem as metas estabelecidas no Simave.

\section{REFERÊNCIAS}

ARAÚJO, Abelardo Bento; SILVA, Maria Aparecida da. O lugar do Sistema Mineiro de Avaliação da Educação Pública (Simave) na busca pela qualidade da educação no Brasil. Roteiro, Joaçaba, v. 36, n. 2, p. 205-224, jul./dez. 2011. Disponível em: <https://www.researchgate.net/publication/268011242_O_ lugar_do_Sistema_Mineiro_de_Avaliacao_da_Educacao_Publica_Simave_na_ busca_pela_qualidade_da_educacao_no_Brasil>. Acesso em: 15 maio 2014.

AUGUSTO, Maria Helena Oliveira Gonçalves. Trabalho docente e organização escolar na rede estadual de ensino em Minas Gerais. 2004. Dissertação (Mestrado em Educação) - Universidade Federal de Minas Gerais, Belo Horizonte, 2004.

AUGUSTO, Maria Helena Oliveira Gonçalves. A regulação das políticas educacionais em Minas Gerais e a obrigação de resultados: o desafio da inspeção escolar. 2010. 279 f. Tese (Doutorado em Educação) - Universidade Federal de Minas Gerais, Belo Horizonte, 2010.

BARBOSA, Liliane Cecília de Miranda. O uso dos resultados do SIMAVE e suas possíveis implicações para gestores escolares e professores: o caso das escolas públicas de Formiga - MG. 2013. Dissertação (Mestrado em Educação) Universidade Federal de Minas Gerais, Belo Horizonte, 2013.

BONAMINO, Alícia; SOUSA, Sandra Záquia. Três gerações de avaliação da educação básica no Brasil: interfaces com o currículo da/na escola. Educação e Pesquisa, São Paulo, v. 38, n. 2, p. 373-388, abr.jjun. 2012. Disponível em: $<$ http://www.scielo.br/pdf/ep/2012nahead/aopep633.pdf>. Acesso em: 27 fev. 2014.

BRASIL. Lei n. 9394/96, de 20 de dezembro de 1996. Diretrizes e Bases da Educação Nacional. Brasília, DF: MEC 1996. Disponível em: <http://portal. mec.gov.br/arquivos/pdf/ldb.pdf>. Acesso em: 1 out. 2013.

BRASIL. Instituto Nacional de Estudos e Pesquisas Educacionais Anísio Teixeira. SAEB. Brasília, DF: Inep, 2014. Disponível em: <http://portal.inep. gov.br/web/saeb/aneb-e-anresc>. Acesso em: 12 set. 2014.

BROOKE, Nigel. O futuro das políticas de responsabilização educacional no Brasil. Cadernos de Pesquisa, São Paulo, v. 36, n. 128, p. 377-401, maio/ago. 2006. Disponível em: <http://www.scielo.br/pdf/cp/v36n128/v36n128a06.pdf>. Acesso em: 27 fev. 2014. 
BROOKE, Nigel. Responsabilização educacional no Brasil. Revista Iberoamericana de Evaluación Educativa, v. 1, n. 1, p. 93-109, 2008. Disponível em: <http://www. rinace.net/riee/numeros/vol1-num1/art7port.pdf>. Acesso em 14 jan. 2015.

BROOKE, Nigel; CUNHA, Maria Amália de A. Avaliação externa como instrumento da gestão educacional nos estados. Estudos \& Pesquisas Educacionais, São Paulo, n. 2, nov. 2011. Disponível em: <http://www.fvc.org. br/estudos-e-pesquisas/avulsas/\%20avaliacao-externa-instrumento-gestaoeducacional-estados.shtml>. Acesso em: fev. 2017.

BURGOS, Marcelo Baumann; SANTOS, Maéve Melo dos; FERREIRA, Patrícia Valesca Gomes. Avaliação, alfabetização e responsabilização: os casos de Minas Gerais e Ceará. Pesquisa e Debate em Educação, Juiz de Fora, v. 2, n. 2, p. 24-44, 2012. Disponível em: <http://www.revistappgp.caedufjf.net/index. php/revista1/article/view/21/19>. Acesso em 10 jan. 2015.

CALDERÓN, Adolfo Ignácio; OLIVEIRA JÚNIOR, Rafael Gabriel de. Sistema de avaliação e rendimento escolar do estado de São Paulo: aprofundando a linha do tempo. In: MARTINS, Angela Maria et al. Políticas e gestão da educação: desafios em tempos de mudanças. Campinas, SP: Autores Associados, 2013.

CALDERÓN, Adolfo Ignácio; RAQUEL, Betânia Maria Gomes; CABRAL, Eliane Spotto. O Prêmio Escola nota 10: meritocracia e cooperação para a melhoria do desempenho escolar. Revista Ensaio: Avaliação e Políticas Públicas em Educação, Rio de Janeiro, v. 23, n. 87, p. 517-540, abr. 2015.

CARVALHO, Gisele Francisca da Silva. Avaliação oficial: subsídios para a compreensão do impacto na prática docente. 2010. Dissertação (Mestrado em Educação) - Universidade Federal de São João Del Rey, São João Del Rey, 2010.

CARVALHO, Gisele Francisca da Silva; MACEDO, Maria do Socorro Alencar Nunes. Avaliação oficial: o que dizem os mediadores da política pública sobre o impacto na prática docente. Estudos em Avaliação Educacional, São Paulo, v. 21, n. 46, p. 253-270, maio/ago. 2010. Disponível em: <http://www.fcc.org.br/ pesquisa/publicacoes/eae/arquivos/1577/1577.pdf>. Acesso em: 10 abr. 2014.

CORREA, Deborah Maciel. Avaliação de políticas públicas para a redução da violência escolar em Minas Gerais: o caso do Projeto Escola Viva, Comunidade Ativa. 2007. Dissertação (Mestrado em Educação) - Universidade Federal de Minas Gerais, Belo Horizonte, 2007.

FERNANDES, Neimar da Silva; FERRAZ, Mariana Santos Botarro; CALIFE, Mariana; SOARES, Tufi Machado; RIANI, Juliana de Lucena Ruas. Análise contextual do Proeb. In: SIMPÓSIO BRASILEIRO DE PESQUISA OPERACIONAL, 40., 2008, João Pessoa. Anais... João Pessoa, 2008. Disponível em: < http://www. din.uem.br/sbpo/sbpo2008/pdf/arq0060.pdf>. Acesso em 8 set. 2014.

FURTADO, Belkis Cavalheiro. Programa de apoio às inovações educacionais: uma proposta da "Escola Sagarana" no Estado de Minas Gerais. Unimep, 200Disponível em: <http://www.anpae.org.br/congressos_antigos/simposio2007/ xxx01.pdf>. Acesso em: fev. 2017.

GATTI, Bernardete Angelina. Avaliação: contexto, história e perspectivas. Oth@ res, Guarulhos, v. 2, n. 1, p. 8-26, maio 2014. Disponível em: <http://www.olhares. unifesp.br/index.php/olhares/article/view/202/76>. Acesso em: 10 jun. 2014. 
HORTA NETO, João Luiz. As avaliações externas e seus efeitos sobre as políticas educacionais: uma análise comparada entre a União e os Estados de Minas Gerais e São Paulo. 2013. Tese (Doutorado em Política Social) - Universidade de Brasília, Brasília, DF, 2013.

MINAS GERAIS. Constituição de 1989. Constituição do Estado de Minas Gerais. 16. ed. Belo Horizonte: Assembleia Legislativa do Estado de Minas Gerais, 2014. p. 281. Disponível em: <https://www.almg.gov.br/opencms/export/ sites/default/consulte/legislacao/Downloads/pdfs/ConstituicaoEstadual.pdf $>$. Acesso em: 25 out. 2014.

MINAS GERAIS. Lei n. 14.694, de 30 de jultho de 2003. Disciplina a avaliação de desempenho institucional, o Acordo de Resultados, a autonomia gerencial, orçamentária e financeira, a avaliação de recursos orçamentários provenientes de economias com despesas correntes no âmbito do Poder Executivo e dá outras providências. Disponível em: < http:/|www.fazenda.mg.gov.br/empresas/ legislacao_tributaria/leis/114694_2003.htm>. Acesso em: 27 jan. 2015.

MINAS GERAIS. Lei n. 17.600, de 01 de julho de 2008. Disciplina o Acordo de Resultados e o Prêmio por Produtividade no âmbito do Poder Executivo e dá outras providências. 2008a. Disponível em: $<$ http://www.almg.gov.br/consulte/legislacao/completa/completa. html?tipo=LEI\&num=17600\&ano=2008>. Acesso em: 27 jan. 2015.

MINAS GERAIS. Secretaria de Educação. Projeto Escolas-Referência: a reconstrução da excelência na escola pública. Belo Horizonte: SEE, 2004a.

MINAS GERAIS. Secretaria de Educação. Projeto Escolas-Referência - guia de estudos: roteiro de estudo das propostas e orientações curriculares. Belo Horizonte: SEE, 2004b.

MINAS GERAIS. Secretaria de Educação de Minas Gerais. Sistema Mineiro de Avaliação da Educação Pública - SIMAVE. Guia de reorganização e implementação do plano de intervenção pedagógica 2008. Belo Horizonte: SEE, 2008b.

MINAS GERAIS. Secretaria de Educação de Minas Gerais. Sistema Mineiro de Avaliação da Educação Pública - SIMAVE. Revista do Sistema de Avaliação - Rede Estadual e Municipal, Juiz de Fora, v. 3, p. 1-114, jan./dez. 2013. Disponível em: $<$ http://www.simave.caeduff.net/wp-content/uploads/2014/07/SIMAVE-RSMR-AMOSTRAL-WEB2.pdf>. Acesso em: 10 jan. 2015.

RIANI, Juliana de Lucena Ruas; SILVA, Vania Candida da; SOARES, Tufi Machado. Análise da avaliação da alfabetização de Minas Gerais: evolução e desigualdade. Estudos em Avaliação Educacional, São Paulo, v. 23, n. 53, p. 126-147, set./dez. 2012. Disponível em: <http://educa.fcc.org.br/pdf/eae/ v23n53/v23n53a07.pdf>. Acesso em: 23 out. 2014.

SILVA, Isabelle Fiorelli. O sistema nacional de avaliação: características, dispositivos legais e resultados. Estudos em Avaliação Educacional, São Paulo, v. 21, n. 47, p. 427-448, set./dez. 2010. Disponível em: <http://www.fcc.org.br/ pesquisa/publicacoes/eae/arquivos/1602/1602.pdf>. Acesso em: 27 jul. 2014.

SILVA, Maria Juliana de Almeida. O sistema mineiro de avaliação da educação pública: impactos na escola fundamental de Uberlândia. 2005. Dissertação (Mestrado em Educação) - Universidade Federal de Uberlândia, Uberlândia, 2005. 
SILVA, Maria Juliana de Almeida. O Sistema Mineiro de Avaliação da Educação Pública: impactos na escola fundamental de Uberlândia. REICE Revista Electrónica Iberoamericana sobre Calidad, Eficacia y Cambio en Educación, v. 5, n. 2, p. 241-253, 2007. Disponível em: <http://www.rinace.net/arts/ vol5num2e/art16.pdf>. Acesso em: 18 fev. 2014.

SILVA, Maria Juliana de Almeida. Regulação educativa: o uso dos resultados de proficiência das avaliações do PROEB por diretores escolares em Minas Gerais. 2011. Tese (Doutorado em Educação) - Universidade Federal de Minas Gerais, Belo Horizonte, 2011.

SILVA, Messias Antônio. A Escola Sagarana: uma ruptura com a concepção da qualidade total, anteriormente implantada na Escola Estadual Padre Eustáquio? 2002. Dissertação (Mestrado em Educação) - Pontifícia Universidade Católica de Minas Gerais, Belo Horizonte, 2002.

SOARES, Jose Francisco; ANDRADE, Renato Júdice de. Nível socioeconômico, qualidade e equidade das escolas de Belo Horizonte. Ensaio: Avaliação e Políticas Públicas em Educação, Rio de Janeiro, v. 14, n. 50, p. 107-126, jan./mar. 2006.

SOARES, Tufi Machado. Modelo de três níveis hierárquicos para a proficiência dos alunos de $4^{\mathrm{a}}$ série avaliados no teste de língua portuguesa do SIMAVE/PROEB-2002. Revista Brasileira de Educação, Rio de Janeiro, n. 29, p. 73-88, maio/ago. 2005. Disponível em: <http://www.scielo.br/pdf/rbedu/ n29/n29a07>. Acesso em: 10 set. 2014.

SOUZA, Maria Alba de. A avaliação da escola pública de Minas Gerais. Estudos em Avaliação Educacional, São Paulo, v. 1, n. 12, p. 25-32, jul./dez. 1995.

SOUZA, Maria Alba de. A experiência de avaliação educacional em Minas Gerais: 1992 a 1998. Estudos em Avaliação Educacional, São Paulo, v. 1, n. 19, p. 57-76, jan.jjun. 1999.

SOUZA, Maria Alba de. Avaliação do rendimento do aluno da escola pública estadual de Minas Gerais no período de 1991-1998: a experiência e seus ensinamentos. Estudos em Avaliação Educacional, São Paulo, v. 18, n. 37, p. 42-90, maio/ago. 2007.

TRIPODI, Maria do Rosário Figueredo. O estado contratual e a nova agenda da educação: o caso de Minas Gerais. Revista @mbienteeducação, São Paulo, v. 6, n. 1, p. 32-50, jan./jun. 2012. Disponível em: <http:/|arquivos. cruzeirodosuleducacional.edu.br/principal/old/revista_educacao/pdf/ volume_5_1/educacao_01_32-50.pdf>. Acesso em: 8 maio 2014.

VIANNA, Heraldo Marelim; ANTUNES, Ana Lúcia; SOUZA, Maria Alba de. Desenvolvimento de um programa de avaliação do sistema estadual de ensino: o exemplo de Minas Gerais. Estudos em Avaliação Educacional, São Paulo, v. 1, n. 8, p. 5-37, jul./dez. 1993. 


\section{KARLA OLIVEIRA FRANCO}

Mestre em Educação pela Pontifícia Universidade Católica de Campinas (PUC-Campinas). Membro do Grupo de Pesquisa em Gestão e Políticas Públicas em Educação da PUC-Campinas, Campinas, São Paulo, Brasil. Membro do Núcleo de Estudos e Pesquisas em Educação Matemática (NUPEm) da Universidade Federal de Uberlândia (UFU). Professora efetiva da rede estadual de ensino de Minas Gerais, Canápolis, Minas Gerais, Brasil franco.o.karla@gmail.com

\section{ADOLFO IGNACIO CALDERÓN}

Professor titular do Programa de Pós-Graduação em Educação da Pontifícia Universidade Católica de Campinas (PUC-Campinas). Pesquisador com Bolsa Produtividade em Pesquisa do Conselho Nacional de Desenvolvimento Científico e Tecnológico (CNPq) - nível 2, Campinas, São Paulo, Brasil

adolfo.ignacio@puc-campinas.edu.br 